\title{
Addiction stigma and the biopolitics of liberal modernity: A qualitative analysis
}

Suzanne Fraser ${ }^{1 *}$, Kiran Pienaar ${ }^{1}$, Ella Dilkes-Frayne ${ }^{2}$, David Moore ${ }^{1}$, Renata Kokanovic ${ }^{2}$ Carla Treloar ${ }^{3}$, Adrian Dunlop ${ }^{4}$

* Corresponding author

E: suzanne.fraser@curtin.edu.au

T: +6139079 2201

1. National Drug Research Institute, Faculty of Health Sciences, Curtin University, NDRI Melbourne Office, 6/19-35 Gertrude St, Fitzroy, Victoria, 3065, Australia

2. Social Studies in Health and Medicine Research Program, Arts, Monash University, Menzies Building, 20 Chancellors Walk, Clayton Campus, Victoria, 3800, Australia

3. Centre for Social Research in Health, Faculty of Arts and Social Sciences, University of New South Wales, Kensington, 2052, Australia

4. Drug and Alcohol Clinical Services, Hunter New England Local Health District, Newcastle 2305, Australia

\section{Acknowledgements}

The research reported in this paper was conducted by researchers from Curtin University's National Drug Research Institute (NDRI), in collaboration with Healthtalk Australia, Monash University and the University of New South Wales' Centre for Social Research in Health, and funded by the Australian Research Council (Discovery Project DP140100996). Suzanne Fraser is funded by an Australian Research Council Future Fellowship (FT120100215). The National Drug Research Institute at Curtin University is supported by funding from the Australian Government under the Substance Misuse Prevention and Service Improvement Grants Fund. 


\section{Abstract}

Definitions of addiction have never been more hotly contested. The advance of neuroscientific accounts has not only placed into public awareness a highly controversial explanatory approach, it has also shed new light on the absence of agreement among the many experts who contest it. Proponents argue that calling addiction a 'brain disease' is important because it is destigmatising. Many critics of the neuroscientific approach also agree on this point. Considered from the point of view of the sociology of health and illness, the idea that labelling something a disease will alleviate stigma is a surprising one. Disease, as demonstrated in that field of research, is routinely stigmatised. In this article we take up the issue of stigma as it plays out in relation to addiction, seeking to clarify and challenge the claims made about the progress associated with disease models. To do so, we draw on Erving Goffman's classic work on stigma, reconsidering it in light of more recent, process oriented, theoretical resources, and posing stigmatisation as a performative biopolitical process. Analysing recently collected interviews conducted with 60 people in Australia who consider themselves to have an alcohol or other drug addiction, dependence or habit, we explore their accounts of stigma, finding experiences of stigma to be common, multiple and strikingly diverse. We argue that by treating stigma as politically productive - as a contingent biopolitically performative process rather than as a stable marker of some kind of anterior difference - we can better understand what it achieves. In turn this allows us to consider not simply how the 'disease' of addiction can be destigmatised, or even whether the 'diseasing' of addiction is itself stigmatising (although this would seem a key question), but whether the very problematisation of 'addiction' in the first place constitutes a stigma process.

\section{Keywords:}

addiction; stigma; neuroscience; performativity; qualitative research 


\section{Introduction}

Definitions of addiction have never been more hotly contested. The advance of neuroscientific accounts has not only placed into public awareness a highly controversial explanatory approach, it has also shed new light on the absence of agreement among the many experts who contest it. Key neuroscience proponent Nora Volkow (Director of NIDA) argues that the approach allows us to understand that addiction is a 'brain disease' and that this disease approach is important because it is destigmatising. The conviction that disease labels destigmatise addiction is also evident among many of NIDA's critics, although the disease models they use do not emphasise the 'brain' in the same way. Considered from the point of view of the sociology of health and illness, the idea that labelling something a disease will alleviate stigma is a surprising one. Disease, as demonstrated in that field of research, is routinely stigmatised (see, for example, Jutel, 2011, for stigma and medical diagnosis). In this article we take up the issue of stigma as it plays out in relation to addiction, seeking to clarify and challenge the claims made about the progress associated with disease models. To do so, we revisit the conceptual terrain established in Goffman's classic work on stigma, reconsidering it in light of more recent, process oriented, theoretical resources, and posing stigmatisation as a performative biopolitical process. Analysing recently collected interviews conducted with 60 people in Australia who consider themselves to have an alcohol or other drug addiction, dependence or habit, we explore their accounts of stigma, finding experiences of stigma to be common, multiple and strikingly diverse. Stigma, it seems, emerges in and through countless activities, relationships and circumstances and plays out in an almost infinite range of ways. This reach and ubiquity invites analysis, especially from the point of view of process given its constant presence. What are the operations of addiction stigma in these instances? What, since it is hardly rare, does it achieve politically? Taking the accounts together, what does it say about drug use per se in Western liberal democratic settings? By treating stigma as politically productive as a contingent biopolitically performative process rather than as a stable marker of some kind of anterior difference - we can better understand what it achieves. In turn this allows us to consider not simply how the 'disease' of addiction can be destigmatised, or even whether the 'diseasing' of addiction is itself stigmatising (although this would seem a key question), but whether the very problematisation of 'addiction' in the first place constitutes a stigma process - a process that for specific biopolitical reasons in need of further, ongoing, examination, remains indispensable to contemporary liberal societies.

\section{Background}


Definitions of addiction and views on the best ways to respond to it have varied significantly over time, and remain multiple and contested. The social science literature on the history and contemporary trajectory of the concept is extensive and has diversified over time to acknowledge the rather different articulations of addiction that occur depending upon the substance under discussion, other issues such as race and gender, and political and cultural variation across time and place (including variations in terminology such as 'dependence', 'substance use disorder' and so on) (see Fraser, Moore and Keane, 2014 for a detailed discussion of this history). The most influential form taken by the idea of addiction recently is that offered by neuroscience. While social and cultural factors are sometimes acknowledged within neuroscientific approaches as contributing to addiction (Fraser, 2013), the "brain reward system' is their main focus. According to NIDA scientists Volkow and Li (2004, p.163), addiction is 'the neurobiology of behaviour gone awry'. As Volkow (2015) explains in a speech entitled 'Addiction: A disease of free will',

If we embrace the concept of addiction as a chronic disease where drugs have disrupted the most fundamental circuits that enable us to do something that we take for granted-make a decision and follow it through — we will be able to decrease the stigma, not just in the lay public, but in the health care system, among providers and insurers.

However, the benefits of the brain disease model have also been questioned. As Rose and Abi-Rached (2014) point out about neuroscience in general, the promise that it would revolutionise medicine has so far failed to materialise. Courtwright (2010) makes a similar observation about its approach to addiction, stating that the view that neuroscience would destigmatise drug use and challenge prohibitionist drug policy is not proving correct. It is becoming evident that labelling addiction a brain disease and then attempting to 'educate' the public about this disease is not producing any consistent change in stigmatising perspectives (see, for example, Meurk et al. [2014] for attitudes research on the brain disease model of addiction). ${ }^{1}$ Indeed, while some may consider Volkow's intervention motivated by a desire to replace a more severe stigma (criminalisation) with a less severe one (pathologisation), this hierarchy of severity too is questionable. In this article we consider these issues of stigma as they relate to addiction. While our data do not allow an extended examination of the neuroscientific approach and its reception, we situate our analysis in its claims about the destigmatising potential of the brain disease model because it represents the principal (highly influential) mode in which more general assertions about the benefits of pathologisation are currently articulated. In turn this allows us to ask bigger questions about stigma and its operations. In our analysis we explore the many manifestations of stigma described by our interview participants, thinking through the political 
operations of stigma more closely than is customary in this field. Finally, we speculate on the kinds of conceptual changes necessary if overcoming stigma really is a societal goal.

\section{Literature review}

Research that takes in experiences and practices of stigma in relation to drug use is extensive and diverse. Along with differences in disciplinary and methodological approaches, there are differences in scale and specificity. In this latter respect the literature takes two main forms (although see, for example, Room, 2005). One form comprises highly specific studies on stigmatising practices in particular settings such as drug treatment services, hospitals and workplaces, on how individuals cope with stigma, and meta-analyses of these bodies of work (Barratt, 2011; Cama et al., 2016; Hathaway, 2011; Keyes et al., 2010; Kulesza et al., 2013; Livingston et al., 2011; Luoma et al., 2007; Radcliffe and Stevens, 2008; Rivera et al., 2014, Simmonds and Coomber, 2009; Treloar and Holt, 2006). This work explores and documents experiences of stigma, and the operations of stigmatising perspectives, and considers the impact of stigma on individuals as well as ways of tackling it. Much of the work is based in broadly psychological or social psychological approaches that tend to attend most closely to the individual or local level, tracking intra-psychic and local dynamics and effects.

The second form comprises broader research projects that incorporate into their analyses the operations of power, marginalisation and inequality in the lives of consumers of drugs. This work offers important, often highly nuanced and contextualised, insights into lives and settings inflected by forces largely inseparable from stigma (e.g. discrimination and exclusion). Ethnographic studies of communities, treatment services and drug markets are excellent examples of this (Bourgois, 2003; 2011; Carr, 2010; Dwyer, 2011; Dwyer and Moore, 2010; Raikhel, 2016; Weinberg, 2005), along with sociological studies of drug-related issues and settings (Fraser and valentine, 2008; Fraser and Seear, 2011; Pennay and Moore, 2010; Race, 2008; Rhodes et al., 2007). This body of work is often driven by an explicit awareness of the operations of power and inequality that form the basis for stigma and discrimination, illuminating the political terrain on which individuals are obliged to act and prompting questions about the scale on which change is required if lasting improvements in the standing of people who use drugs are to be achieved. Illuminating the diverse forms of disadvantage and discrimination people who use drugs experience, it analyses the role of gender, race, economic status, neighbourhood, sexuality and many other dimensions in these experiences. Taken together, these two bodies of research draw attention to the ubiquity of addiction-related stigma, and its effects on people who use drugs. 
Alongside this work it is useful to consider the small body of other publications that analyse related health issues in ways that frame stigma differently, attending more searchingly to its specific relationship to power. Parker and Aggleton's (2003) article on stigma and HIV is an exemplar here in that it uses Foucault's work to embed stigma more clearly than is often the case in the production of power. As they put it (2003: 17), stigma is 'central to the establishment and maintenance of the social order'. This work goes some way towards bringing into focus the need to see stigma not merely as a side effect of misconceptions or of individual proclivities towards aggressive exclusionary judgmentalism. The authors argue instead that,

stigma is deployed by concrete and identifiable social actors seeking to legitimize their own dominant status within existing structures of social inequality. (2003: 18) There is no doubt that such interventions in the accounting for stigma are productive. The analysis we conduct here, however, establishes a different emphasis and thus a different account. In brief, our approach aims to rely less heavily upon the sovereign agency sometimes privileged in Parker and Aggleton's diagnosis of the emergence and perpetuation of stigma. Instead it emphasises the mutual co-production of power and subjectivity, placing stigma into a performative ontological framework more attentive to the socially constitutive role of such phenomena and, we think, allowing useful insights into stigma's ubiquity and persistence. We turn to Judith Butler's philosophical resources on performativity here, finding in it tools for re-posing stigma as a performative biopolitical technology of power, one that constitutes the very conditions under which legitimate subjects emerge. In what follows we begin to raise questions about the biopolitical functions and operations of stigma, linking these to the aforementioned claims about the destigmatising effects of disease labels.

\section{Approach}

According to Erving Goffman (1973 [1963]), stigma exists where a personal attribute is viewed negatively in society, and where the affected individual is marked by that attribute in such a way that she or he is aware of the potential or actual negative judgements of others. In this sense the individual feels a sense of being either already 'discredited' by the attribute, or else potentially 'discreditable' in that negative judgement would follow the discovery by others of the attribute in question. In both cases, the individual is shaped by the sense of external judgment. As Goffman puts it,

The stigmatized individual tends to hold the same beliefs about identity as we do: this is a pivotal fact ... the standards he [sic] has incorporated from the wider society equip him to be intimately alive to what others see as his failing, inevitably causing 
him, if only for moments, to agree that he does fall short of what he really ought to be. Shame becomes a central possibility... (Goffman, 1973 [1963]: 17-18) Goffman's work has been used productively to examine a wide range of social issues, including, as we have seen, addiction (Fraser and Treloar, 2006; Neale, Nettleton and Pickering, 2011). It has also been adapted and refined, most notably by Graham Scambler who further conceptualises the distinction between 'discreditable' and 'discredited' identity in his influential study of epilepsy (1989). Here he offers two related concepts: 'felt' and 'enacted' stigma, drawing a distinction between the expectation of negative judgement, and the direct experience of negative judgement. This distinction allows Scambler to acknowledge the unique, sometimes powerful, negative effects of maintaining silence around an attribute that may be expected to attract stigmatisation (1989: 57). Indeed, where silence is maintained, the possibility of encountering non-stigmatising, accepting responses from others is lost.

In this respect, and also simply because stigma emerges out of the relationship between 'normality' and otherness, stigma should, Goffman says, be articulated through a language of relationships, not only of attributes (1973 [1963]: 13). Here he is pointing to the sense in which attributes are not discrediting in themselves: they are only discrediting as a result of the socially produced meanings attached to those attributes. According to Goffman (1973 [1963]: 14), there are three types of stigma or 'undesired difference' that distinguish individuals from the 'normals':

1. 'abominations of the body', e.g. deformities

2. 'blemishes of individual character' and;

3. 'tribal stigma of race, nation and religion'

What are the implications of these differences? As Goffman puts it (1973 [1963]: 15),

By definition, of course, we believe the person with a stigma is not quite human [...] We construct a stigma theory, an ideology to explain his inferiority and account for the danger he represents, sometimes rationalizing an animosity based on other differences such as social class.

The account Goffman offers here fits neatly with addiction. The 'addict' is not quite human. She or he may be marked by all three of Goffman's differences: the intoxicated or dependent body is an abomination - the product of a weak will, belonging to a tribal underclass of deviant and damaged souls. Discrimination follows the recognition of difference, as does a theory to justify the discrimination. Where the addict's response is 'defensive' (resistant, angry or dismissive), this is simply treated as 'a direct expression' of the defect itself, further confirming our assessment and the treatment that accompanies it (see Fraser, 2008). 
The stigmatised respond in various ways, managing and confronting the processes by which they are marginalised and othered in their encounters with the 'normals'. According to Goffman, the main focus of his book is this encounter. While Goffman makes a point of framing stigma as a social process based on relationships, a key characteristic of the book is its emphasis on affected individuals and on questions of how stigma impacts on them, how they cope and how they relate to others (1973 [1963]: 151). This is of course an important approach because it emphasises the agency and subjecthood of those affected by stigma. As a result of it, however, Goffman pays little attention to questions of why particular features or issues come to be stigmatised, or what is achieved at a political level by stigmatisation.

It could be argued that the absence of an analysis of the production of stigma has a kind of naturalising effect. By this we mean that it tends to present stigma as inevitable, the result of the intrinsic need for sameness within societies. As Goffman puts it, the management of stigma is 'a general feature of society, a process occurring wherever there are identity norms' (1973 [1963]: 155). He goes on to express the view that, 'the role of the normal and the role of the stigmatized are parts of the same complex' (1973 [1963]: 155). It is difficult to greet this assessment as anything but concerning. While it would perhaps be naïve to ask for a world in which difference goes unremarked and we all live in an atmosphere of kindly and frictionless mutual acceptance, the severity of some kinds of stigma means merely accepting this dynamic as inevitable and ubiquitous is not a viable ethical response. The stigmatisation of drug use and addiction finds extreme expression especially in legal contexts, where policing and incarceration are key elements, and where it supplies the logic for the execution of drug smugglers (China, Indonesia, Iran, Malaysia, Saudi Arabia, Singapore, Vietnam) and even extrajudicial killings with impunity (most notably in recent times, the Philippines). Such events render resignation to the inevitability of stigmatising reflexes impossible. Instead they prompt urgent questions about difference, the need to reconsider current judgements about drug use and addiction and, to put the issue simply, our ability to live with difference and the Other. This question of otherness, its place in workable societies, its meaning and how it is engaged, is an extremely pressing one, and may indeed require sustained theoretical and empirical attention if progress towards greater understanding is to be made (see also [omitted, forthcoming]; Weinberg, 2005).

Some of Goffman's observations do point towards a broader political way of understanding stigma processes that might be built upon in relation to drug use and addiction. For example, he notes towards the end of the book that: 
the perceived undesirability of a particular personal property... has a history of its own, a history that is regularly changed by purposeful social action. (1973 [1963]: 164-5)

The same could indeed be said for addiction, which as many have noted emerged in the $18^{\text {th }}$ and $19^{\text {th }}$ centuries, has played out via varying explanatory frameworks since then and remains controversial. It is in this sense, in the resilience and persistence of addiction stigma, even as its terms and terrain shift over time, that a different account of stigmatisation and its functions is invited.

Taking up a theoretical trajectory that postdates Goffman's valuable work, in particular Judith Butler's performative ontology, we re-pose stigma as a biopolitical technology of the social: a performative process that operates in the service of normative social relations. If we turn to Butler's account of sex in her book Bodies that Matter (1993), we find tools of considerable value for our analysis. So, for example, Butler (1993: 2) makes clear the productive role of simultaneously limiting phenomena such as binarised biological sex:

'Sex' is, thus, not simply what one has, or a static description of what one is: it will be one of the norms by which the 'one' becomes viable at all, that which qualifies a body for life within the domain of cultural intelligibility.

Further, she explains that (1993: 3), 'the subject, the speaking "l", is formed by virtue of having gone through such a process of assuming a sex'. Spelling out the dynamic under consideration here, she adds:

the subject is formed through the force of exclusion and abjection, one which produces a constitutive outside to the subject, an abjected outside, which is, after all, 'inside' the subject as its own founding repudiation (1993: 3).

In these statements Butler is pointing to the necessary role the adoption of a recognisable sexed identity plays in the admittance of each subject into ordinary social life. Importantly, Butler's book also offers a critique of just how the standard binary model of sex is constituted (through the circulation of gender discourse), thereby ensuring her account is not an essentialising one. We have a similar task to perform here. If the subject only becomes viable through its accession into the realm of binary sex and the proclamation of conventional sex/gender alignment (my body is female and I am a woman), a similar process operates in relation to the accession into autonomous, sober, free and rational subjecthood. In Butler's analysis, the outside of legitimacy comprises all those whose sex, gender and sexuality do not align in normative ways. In our analysis, the outside of legitimacy comprises all those whose relationship to drugs does not align with normative understandings of autonomy, sobriety, freedom and rationality. ${ }^{2}$ 
Linking Butler's account of the constitutive outside to Goffman's observation that 'the role of the normal and the role of the stigmatized are parts of the same complex' we can argue that stigma is more than a misunderstanding or deficit of knowledge or feeling to be solved or supplemented. It is a process of social production. Stigma, that is, is not simply a thing, a mark, nor is it even just a relationship. It is not just a local or intra-psychic process where individuals form 'in-groups' and 'out-groups' (Simmonds and Coomber, 2009). It is a biopolitical technology of power that allows certain subjects legitimacy and not others, and further, constitutes the conditions under which legitimate subjects emerge. This is perhaps why it is not readily or enduringly dismantled by 'education', however well-meaning, why it inheres even in institutions such as healthcare. It is a founding process of social production, and the particular issues through which it operates in any given society (binary sex, sobriety) tell us much about the unexamined self-image of that society, and the many other related phenomena on which that self-image relies. It could be, for example, that the figure of the irrational addict forms one of the last remaining consensus Others to the now beleaguered 'modern interlude' in which Enlightenment notions of rationality, objectivity and transparent reality hold sway (Fraser, Moore and Keane, 2014; Keane, 2002; Latour, 2010; Sedgwick, 1993).

In what follows we examine the accounts of stigma provided in our interviews, considering them in light of Goffman's observations about stigma and Butler's insights into the political productivity of abjection. In doing so, our approach to abjection focusses on its socially performative operations. In this respect its emphasis is rather different from other important approaches to abjection, such as Julia Kristeva's profoundly influential work (1982) which foregrounds explicitly emotional dimensions of shame, horror and repulsion. All these dimensions also operate in the abjection discussed here (they are of course in part what give it its force, and both Butler and Kristeva operate on psychoanalytic theoretical terrain), but our main concerns are liberal social processes and political effects.

\section{Method}

The qualitative research project on which this article is based was designed to gather personal accounts for presentation on a web-based resource on addiction experiences (www.livesofsubstance.org). The project is a collaboration with Healthtalk Australia (http://healthtalkaustralia.org), a research consortium that conducts qualitative research into personal experiences of health and illness. Healthtalk Australia collaborative projects use a qualitative methodology developed by Oxford University's Health Experiences Research Group (HERG, 2010). Following this methodology, in-depth qualitative interviews were conducted with 60 people who responded to a recruitment flyer that opened with the 
question: 'Do you consider yourself to have a drug habit, dependence or addiction?' The flyer was circulated through alcohol and other drug sector newsletters, treatment services, and peer advocacy organisations. Those who responded were screened to ensure range in gender, age, drug type(s), and treatment experiences. All described ongoing $(n=47)$ or past $(n=13)$ regular use of a range of licit and illicit drugs including alcohol, cannabis, crystal methamphetamine, heroin and benzodiazepines. Demographic details are presented in Appendix 1.

Interviews took place during 2014 and 2015 in urban and regional Victoria and New South Wales, Australia. Following an open-ended invitation to 'tell us their story', participants were asked about their experiences of living with an alcohol or other drug habit, dependence or addiction, including consumption in daily life, managing relationships, health and well-being and future plans. All interviews were conducted in person (by authors [omitted] and project staff) and were audio-recorded and transcribed. To protect participant identities, each was given a pseudonym and all identifying details were removed from the transcripts. The interviews were then analysed using an iterative inductive approach in which a preliminary list of codes was drawn up based on themes emerging from the data, as well as the literature and knowledge of key debates. The data were then coded with the aid of the NVivo qualitative data management software.

This study was approved by [omitted] University's Human Research Ethics Committee (HR 55/2014). All participants provided informed written consent.

\section{Analysis}

As we have noted, many participants described experiences of addiction-related stigmatisation. They talked at length about the impact of stigma on their everyday lives, including how it shapes their experiences of healthcare, their relationships with family, friends and their work. The sections that follow break up kinds of stigma according to context to allow us to focus on the variety of settings within which participants describe encountering stigma. Importantly, however, such experiences overlap for many, forming not individual islands of discomfort or abuse, but the very fabric of everyday life.

\section{The healthcare system}

Perhaps unsurprisingly, given the extensive literature documenting the persistence of stigma within the health system (e.g. Anstice et al., 2009; Henderson et al., 2008), this is one of the most commonly cited contexts participants describe as stigmatising, including those contexts 
offering harm reduction services. Some participants describe experiences when they felt healthcare professionals treated them differently from other patients, with several commenting that they feel like staff 'look down on' them. As David (M, 25, unemployed, heroin) explains in relation to his experience of filling his methadone prescription:

Just at the chemist, I feel like they are looking down on us. They don't treat us [like] a normal patient. Like, we'd go in there for a prescription [and we] are always second best. Like [the staff will] push you to the side or push you back, and deal with their people first and then deal with the 'druggies'. That's what we look like [to them]. Here David is describing what Scambler (1989) calls enacted stigma. Similarly, Dean (M, 35, works in hospitality, methamphetamine) says he has been refused service at chemists when trying to access sterile injecting equipment.

Getting needles when you need them is a hard deal [...] Even going to chemists and asking them, they're like, 'No, no [...] we don't have them' [...] I just sort of wanted to get out of there [after being told that] because I felt about this [small]. So yeah, I went to a few different ones. One big one that I knew stocked them around here, and they said, 'No' as well, and I was just like, 'Okay'.

Like David, Dean describes enacted stigma, but he also goes on to spell out the shame this stigmatising process generates for him, the sense in which the stigmatising process instigated a particular sense of self, and particular experiences of 'felt stigma' (Scambler, 1989: 57).

In addition, several participants say they found it hard to get medication for pain relief because of their medical histories of alcohol and other drug dependence. For example, when George (M, 58, not working due to illness, alcohol) was injured, he says he was denied adequate pain medication due to his 'history of drug use'.

l'd actually been attacked and had fractured my back and they sent me out of the hospital with Panadeine [paracetamol and low-dose codeine]. I couldn't even get [Panadeine] Forte [paracetamol and higher-dose codeine] because they knew I had a past history of drug use. So they wouldn't give me anything stronger than Panadeine. I mean it's ridiculous. I had a fractured back.

Similarly, Zadie ( $F, 33$, works in the health sector, heroin) describes being refused treatment for a health condition because, she says, the doctors 'assumed [she] was just trying to scam some opiates'. Commenting on being denied pain medication, she says,

[If] you treat people like this, you leave them with little [...] option other than to do what they can to deal with that pain. And certainly, it was easier to go and score some illicit drugs to deal with it. What else was I going to do? Zadie's experience of hospital care after an accidental overdose is especially striking: 
I was unconscious and I came to in the hospital [...] I became conscious but I couldn't move a muscle [...] I could feel pain but I couldn't move, and I could hear what the doctors and the paramedics were saying about me [which was] just really derogatory, you know: 'Stupid fucking junkie, [we] get them all the time'. It upsets me even thinking about it [crying]. They were being very, very rough with my body. There was no care.

Past experiences of stigma and discrimination in the health system mean that some of our participants are hesitant to discuss their alcohol or other drug consumption with health professionals, or access healthcare. This has several important implications. Most concretely, it can mean that people seek medical help belatedly by which stage initially minor health problems may have become more serious and difficult to treat. More abstractly, this process of generating avoidance and even shame operates to exclude and render abject the drug using subject, producing invisibility, constituting the normal health subject by erasing the undesirable. Following Goffman, the extracts above suggest that people who consume drugs routinely enter healthcare settings keenly aware of their 'discreditable' identities, already subjects of felt stigma, and all too often of enacted stigma. How can felt and enacted stigma be reliably separated here? We would argue they cannot, and that, in keeping with the performative approach to stigma outlined earlier, wherever felt stigma is facilitated, this facilitation needs to be understood as a form of enactment. Here we begin to view Goffman's stigma, and the abjection Butler elucidates, more as a systemic process, one that constitutes legitimacy and abjection at once, a process that cannot it seems establish intelligibility and belonging without also establishing unintelligibility and exclusion.

\section{The workplace}

Another key area in which participants describe stigma is employment and the workplace (other research illuminating this issue includes van Olphen et al., 2009; Baldwin et al., 2010; Earnshaw et al., 2013). Some say they decided not to disclose their drug consumption to their employers because they were concerned they would be judged and lose their jobs. As Jenna (F, 31, cannabis, studying) puts it, 'I don't think people judge based on performance $[\ldots]$ If they think you're [a drug] user, then [...] the judgment is made that you are not employable'. Dean (M, 35, works in hospitality, methamphetamine) says that if colleagues noticed injecting track marks on his arms, they would assume he has a 'problem'.

But yeah, I think every [workplace has a...] lot more of a sort of relaxed feel when it comes to alcohol. But when you go to work with track marks, you don't even 
necessarily have to be using at work, or under the influence [...but] there's just this thing that you've got a problem [...so] most of the time [I wear long sleeves at work]. Here Dean again describes the work individuals do to manage 'discreditability', but we can also consider his words from the position being developed in this article, that of the process of stigmatisation, the constitution of the 'normal' - the re-enactment of alcohol consumption and all that goes with it as normal - precisely through the abjection of other kinds of consumption.

Some of those interviewed were recipients of opioid pharmacotherapy treatment, and described particular challenges relating to managing employment and participation in this form of treatment. A few described avoiding telling their employers that they were having treatment for fear of being judged or even losing their jobs, even though limited dispensing hours meant difficulties accessing dosing. As David ( $M, 25$, unemployed, heroin) explains:

[I never talked to my boss about going to the chemist...] I just didn't want him looking at me as a druggie [...] I always had to [get my methadone dose] before work or after work. And with getting there on time and just a lot of hassle just to make it to the chemist, I thought to myself, it's not worth [trying to get my dose during work hours. If I told my boss he would] just look at me different and I know I'm better than that [...I was] scared to get sacked or discriminated against.

David's account makes clear the threat of discreditability that shapes many participants' lives, and in particular the role this threat plays in creating workplaces putatively untouched by illicit drug use. It also suggests, as the previous section indicates, that despite its supposedly non-judgmental approach based in medicine's aim to cure or alleviate disease, the healthcare framework posited by 'treatment' does not necessarily resolve the potential for stigmatisation. Here again we see addiction stigma operating as a biopolitical technology allowing certain subjects legitimacy and not others, discrediting the drug using subject as incapable and 'unemployable', and rendering disclosure unthinkable. As we saw in the context of the health system, one effect of this is that it renders the drug using subject invisible in the workplace, reinforcing the idea that drug use and productive work are inimical.

\section{The criminal justice system}

Experiences of stigma in the criminal justice system are also described by participants (see also Radcliffe and Stevens, 2008). Some describe experiences in which police officers, lawyers or judges expressed negative attitudes towards them or treated them unfairly. Some point out that the criminalisation of drugs contributes to the stigma surrounding them. As Jim (M, 21, studying, cannabis) explains, 
I think if [cannabis] was legal, there wouldn't be this whole stigma around it. And, like, the anxiety and stuff that comes when people are high, I think, is based around the fact that you have done something wrong now and you can get in trouble.

Jim's comment is important for the position we advance in this article. As he notes, the relationship between stigma and institutional and legal arrangements should not be ignored. Measures that treat stigma as a fundamentally individual phenomenon that can be tackled through education and interaction with stigmatised individuals not only ignore its institutional dimension, but actively obscure and naturalise it, potentially ushering in abuses of power (as the next example suggests). Peter ( $M, 41$, unemployed, heroin) describes the stigma of track marks and the related sense of being unfairly targeted by police. He reports being strip searched on one occasion because police suspected he was carrying illicit drugs:

As soon as the police see [...track marks on forearm], just, they know and they do treat you different. They treat you with such little respect. l've had them drag me into an alley before and fully strip search me in an alley, just because they thought I had drugs on me. They thought I was dealing, and I had nothing on me. And anyone could've walked down that alley. And just little things like that, and your lack of dignity really. They really do take [that] away from you.

Peter characterises being publicly strip searched as a 'little thing', yet he also says encounters of this kind deprive him of his dignity. Misja (M, 40, not working due to illness, cannabis and heroin) too says the police are very judgmental about people with addictions and often search them for no reason.

If you get pulled over in my area, the first thing [the police] say is, 'What are you doing in this area? It's a known drug area. Why are you here?' [... They think] just because someone's a drug addict, they've got to be up to no good. And I don't find that right at all because, like, I'm a drug addict, and I don't cause any trouble any more and I don't want to cause any trouble for anyone. But yeah, I just don't like how they are so judgmental, and they actually taunt [you]. Yeah, when they pull you over and they try to pin you for something, they've got to search you [...] To be pulled over in public and searched for no reason at all, just because you are walking down the street, that's not right.

Some participants focus on other aspects of the criminal justice system, including legal processes. When Dawn (F, 38, works in manufacturing, alcohol) was facing assault charges and hoped to access an alcohol treatment service, she felt that her lawyer condemned her as merely a 'drunk'.

The guy that represented me [...] I really felt that he was judging me for what l'd done. He was also a lawyer for kids and so when he was representing me, maybe I 
just felt that he $[\ldots]$ really felt that I didn't deserve to go to rehab $[\ldots]$ I really felt that he thought that I should just be thrown into jail and I was a drunk.

While individualised education might appear to be a logical response to stigmatising and discriminatory approaches, examples of this kind suggest otherwise. First, the nature of stigma as a process means potential targets such as Dawn are understandably primed for negative judgements. Tackling the issue piecemeal by educating relevant service providers is unlikely to produce the sea change that would alter Dawn's expectations, that is, her experientially based sense of felt stigma. Second, it is difficult to argue that highly trained professionals such as lawyers do not already have sufficient access to information about drug use, or the skills and obligation to find it. It is also difficult to argue that what is missing is direct contact with members of the stigmatised group. Dawn's personal history includes experiencing violence at the hands of the father of her eldest daughter, anxiety and depression, relationship breakup and the teenage pregnancy of her daughter. All these aspects of her life were available to her lawyer. Whether he did indeed judge Dawn as harshly as she believed (and her perceptions in themselves tell us much about the operations of stigma), it seems unlikely given her comments that he actively attempted to relieve her very predictable fears.

\section{The media}

Another key area of addiction stigma discussed by our study participants was the media (see also Cape, 2003; Fraser, 2006; Swalve and DeFoster, 2016). Several point out that media coverage can be sensationalist, exaggerating the harms of drugs and contributing to misinformation and damaging stereotypes. A few say they avoid news media reports on drug use for this reason. As Scott (M, 25, studying and working in hospitality, alcohol) puts it:

You open The Herald Sun or even The Age [newspapers, the latter a respected broadsheet], like, I don't even bother. I just don't read it, or it just goes in one ear and out the other [...] because [the media presents] like such an extreme view of these people, like me and my friends [who take drugs].

Harry (M, 52, works in the arts, heroin) offers a specific example of how the media reinforces stigma by presenting inaccurate information and negative stereotypes about drug consumption.

[...According to the media] everyone falls into this category [of being addicted] They're the junkie, you know, they're the useless person on the street, they're the bottom feeders, you know [...] It's not questioned in the mainstream media and that's the unfortunate thing [...that there is] that level of stigma [in the media]. According to Artemis (M, 28, works in education, party drugs) media coverage of crystal methamphetamine consumption in particular exaggerates rates of 'problematic use', failing 
to acknowledge that many use it without developing problems. This, he says, reinforces the stigma surrounding it.

Certainly in the media, addiction is the only discourse when it comes to drug use. I mean, we have to only look to the recent coverage of crystal meth use to like shake our heads and wonder, you know. Everyone is addicted to crystal meth, I take it. Not that crystal meth isn't very addictive and problematic for some people, there's no question about that, but [...] there are [many more] who use without issue [...] In terms of addiction, I mean it's stigmatising.

Others talk directly about how stigmatising media reports impact on their everyday lives. For example, Nick (M, 50, not working due to illness, heroin) says that news reports reinforce negative attitudes, and he believes this has affected his relationships:

[Living with a drug habit] you lose contact with friends [...] Friends that can help [...] are no longer around [...] because I think [...] they read the paper and the news, and they see crimes committed by people to get drugs. They put me in that category, I suppose.

As with the healthcare system and the criminal justice system, the media are understood by participants to be key agents in the stigmatisation of drug use and of people engaged in it. Rather different here, however, is the degree of personal connection with the stigmatising process. In the previous sections participants described very direct experiences of stigma based on contact with individuals who address them personally. In the context of media discourse, the biopolitical effect is more indirect and general, but no less significant. In these cases individuals are not personally addressed, but are nonetheless acutely aware of the impact the media have on how their lives are understood and valued, and how normalisation and abjection are produced.

\section{Family and friends}

Some participants' most painful experiences of stigma are described as occurring within family and friendship networks (see also Earnshaw et al., 2013). One participant, Nick (M, 50 , not working due to illness, heroin), says his family discriminate against him because of his heroin consumption and this causes him pain.

The relatives didn't want their kids associating with me any more - my cousins even though I didn't encourage them to take drugs or anything of the kind. Yeah, that hurt a bit [...] It had a big impact. [...] They don't trust me. And they think that a user is a junkie, a stereotypical junkie that'll steal from anybody. 
Similarly, Bobby ( $M, 49$, not working due to illness, heroin and alcohol) explains that his mother judges him for taking drugs and refuses to let him stay with her when he visits from out of town.

I can sense the discrimination from my own mother. Like, last time when I had my accident, I went [interstate to visit her. At the time she was] in hospital. So I got all the way [there] and [...] I'm her son and I needed somewhere to sleep, and my own mother doesn't want me to sleep at her place. That says a hell of a lot. That means my mother has written me off [...] I've even told her like, 'There are no drugs' and everything, but her actions speak louder. So you can lose your own mother because she has got preconceptions about drug use.

Stigma and discrimination lead some participants to avoid disclosing their drug use to family and friends. For example, echoing Goffman's observations about the status of the stigmatised as not quite human, Harry ( $M, 52$, works in the arts, heroin) says,

Because of [heroin's] prohibition and [the fact] that it's stigmatised, you can't admit to people around you, even sometimes close friends, that you might use that drug.

Because they will think you're a [...] 'junkie', which [...] basically frames you as being something less than human or less than normal.

Perhaps most importantly of all, along with all these specific descriptions of cases or instances of stigma - in healthcare, the criminal justice system, personal relationships and so on - it is essential to note that some participants describe experiences of many different kinds of stigma. For example, during the course of his interview Harry describes encountering stigma in his workplace, the healthcare system, the media and his extended family. While our interview method encouraged participants to speak freely about their experiences, the effect was largely to elicit examples. Harry's comments, when taken together, are a reminder of how persistent, widespread and endemic such stigmatisation can be. Indeed, this article's approach to stigma - treating it as a biopolitical technology of power - prompts us to see it as a broad process, unlikely to inhere only in one or another encounter or situation.

\section{Challenging stigma and discrimination}

Importantly, some of our participants say they prefer to talk openly about their drug use in an effort to overcome shame and challenge negative stereotypes. As $\operatorname{Jim}(\mathrm{M}, 21$, studying, cannabis) says, 'I suppose I am already labelled as a drug user and I don't deny it. I tell people I use drugs [...] so I'm not really scared of that stigma at all'. Related to this, some people criticise the idea of addiction or dependence, saying it implies illness and suffering. Challenging this view, they describe regular consumption as an important part of, rather than 
a threat to, their rich and fulfilling lives. Indeed, some argue that stigma actively causes drugrelated harm by turning drug use into the source of shame and a sense of failure and illegitimacy. Kate ( $F, 36$, works in the health sector, prescription drugs and methamphetamine) links these processes to prohibition, its exclusionary action and its automatic creation of criminals:

Branding someone an addict, it's like they're not part of the community any more, they are a criminal, they're like not someone you'd want in your home or in your life or around your kids. And yeah, there's that really big separation [...] Then you are [thinking] 'well it's an addiction, I have a problem and I need to seek help', and then if you don't seek help it's like, 'I'm not seeking help for my addiction, so I am a bad person' or 'I'm not living my life responsibly, I'm not contributing to the community, I'm not this and I'm not that'. And I mean all that comes back to prohibition.

The relation between criminalisation of drug use and the performative enactment of people who use drugs and 'addicts' as irresponsible failed citizens can be seen as a key part of the stigmatisation process and its function as a biopolitical technology of power. Of course, alcohol does not fit neatly into Kate's account in that it is not subject to prohibition. But as Dean's earlier comments about the status of drinking versus injecting drug use suggests, alcohol consumption is viewed very differently from illicit drug use and, while also stigmatised, 'alcoholism' tends to be identified by markers and thresholds that also differ significantly from illicit drugs. This reminds us, as do the varied accounts in previous sections of this analysis, that the operations of stigma are contingent on a range of other processes and phenomena, including the legal status of different drugs, the 'diseasing' of addiction, the governing ideal of free will and the related assumption that drug use constitutes a threat to the proper rational, choosing subject.

\section{Conclusions}

In the analysis presented here we have spelt out the many experiences of stigma reported by the participants in our study. In doing so we have highlighted the persistence of addiction stigma in a context where disease models, most influentially right now the brain disease model, ought if expectations are correct to be reducing such experiences, and we have raised the need for new approaches that better understand the role of stigma. In response to this need we have elaborated the performative dimensions of stigma, the ways in which it enacts certain abject subjectivities, sensations and material expressions of exclusion. Given the continuing ubiquity of addiction stigma despite efforts to reduce it by presenting addiction as a disease, we are obliged to consider whether such attempts to destigmatise it may be naïve. It may be that it is more productive to ask what this stigmatisation achieves, given its 
place in the seemingly unremitting engine of modernity. If 'the role of the normal and the role of the stigmatized are parts of the same complex' (Goffman 1973 [1963]: 155), what is the 'complex', how cohesive is it, and how might it be interrogated and undermined? To pursue these questions we must consider addiction not so much as a stigmatised state but as a linguistic and taxonomical mechanism by which stigma is materialised. This, we would argue, includes the medicalised terminology of 'dependence' and 'substance use disorder'. From this point of view, addiction should not be reified as a fixed attribute that attracts stigma, one that, as Nora Volkow has argued, can be destigmatised if only we see that it is a sickness of the brain characterised by a 'diseased' 'free will' (2015), or even as essentially a problem ruthlessly mobilised in the 'service of power' (Parker and Aggleton, 2003). Instead it is a biopolitical designation at the centre of a profound process in which a constitutive outside of irrationality and dependence emerges to consolidate the modernist centre of rationality and autonomy (Sedgwick, 1993). In practical terms, that is, addiction is a means by which contemporary liberal subjects are schooled and disciplined in the forms of conduct and dispositions required to belong, and to count as fully human. Thus, while for some the designation 'disease' offers those affected access to compassion and a kind of destigmatisation, another perspective suggests it merely entrenches stigma by rendering people both sick and not competent to 'speak back' against this rendering. Moreover, in cases where people who use drugs try to comply with liberal expectations such as the responsible use of sterile injecting equipment but are turned away at chemists, or participation in paid employment but cannot access treatment dosing at suitable times, their abjection is doubled, and indeed somewhat circular. In many respects, then, the loss of legitimacy our participants report suffering cannot be remedied by disease concepts indeed it may be magnified by them.

Lest we conclude along the lines already questioned above - that stigmatisation is an inevitable or natural aspect of the production of cohesive societies - it is important to note that Butler also observes (1993: 3 ) that the abjection on which the subject is grounded always threatens to come to light, and that its consequences cannot be fully controlled. Her work highlights scenarios of gender disruption: of active sex/gender resistance, as well as the exposure of gender's arbitrariness via 'failed' gender iterations. Similarly, our work highlights both the active resistance of people who use drugs to the stigma(tisation) of addiction, and the disruptions that occur through the inadvertent 'failure' to reiterate the supposedly fundamentally free 'non-addicted' subject. Such instances of disruption should not be seen merely as mistakes or as moments of misguided or doomed protest. As Butler says (1993: 3 ), 
The task will be to consider this threat and disruption not as a permanent

contestation of social norms condemned to the pathos of perpetual failure, but rather as a critical resource in the struggle to rearticulate the very terms of symbolic legitimacy and intelligibility.

This indeed is our task too, if we genuinely wish to eradicate the stigma so consistently and movingly described by the participants in this study. Our aim must be to rearticulate the very terms of symbolic legitimacy and intelligibility addiction concepts exist to serve. 
Table: Data characteristics $(\mathrm{N}=60)$

\begin{tabular}{|c|c|}
\hline 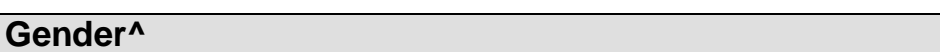 & Number \\
\hline Men & 35 \\
\hline Women & 25 \\
\hline \multicolumn{2}{|l|}{ Main preferred drug* } \\
\hline Alcohol & 11 \\
\hline Cannabis & 14 \\
\hline Opiates & 14 \\
\hline Stimulants & 12 \\
\hline 'Party drugs' (e.g. MDMA, GHB, Ketamine) & 4 \\
\hline Prescription \& over-the-counter drugs & 5 \\
\hline \multicolumn{2}{|l|}{ Age } \\
\hline $18-29$ & 14 \\
\hline $30-39$ & 20 \\
\hline $40-49$ & 14 \\
\hline $50+$ & 12 \\
\hline \multicolumn{2}{|l|}{ Cultural and ethnic background } \\
\hline Australian & 31 \\
\hline Australian Aboriginal & 2 \\
\hline New Zealander & 1 \\
\hline Polynesian & 2 \\
\hline North-West European & 12 \\
\hline Southern \& Eastern European & 4 \\
\hline North African \& Middle Eastern & 1 \\
\hline South-East Asian & 1 \\
\hline North-East Asian & 2 \\
\hline North American & 2 \\
\hline Southern \& Eastern African & 2 \\
\hline \multicolumn{2}{|l|}{ Sexual identity } \\
\hline Heterosexual & 41 \\
\hline LGBTIQ+ & 18 \\
\hline Unspecified & 1 \\
\hline \multicolumn{2}{|l|}{ Education level } \\
\hline Secondary & 26 \\
\hline Post-secondary & 12 \\
\hline Tertiary & 22 \\
\hline \multicolumn{2}{|l|}{ Employment status } \\
\hline Working/studying & 41 \\
\hline Not working/studying & 19 \\
\hline \multicolumn{2}{|l|}{ Location } \\
\hline Major urban - Victoria: Melbourne & 21 \\
\hline Regional - Victoria: Bendigo & 9 \\
\hline Major urban - New South Wales: Sydney & 19 \\
\hline Regional - New South Wales: Byron Bay, Lismore \& Nimbin & 11 \\
\hline
\end{tabular}

${ }^{\wedge}$ All participants identified either as male or female.

* Some participants described consuming only one drug, while others talked about two or more. The table lists the drug that participants identified as their primary preferred drug.

Reporting of cultural and ethnic background follows the Australian Standard Classification of Cultural and Ethnic Groups, developed by the Australian Bureau of Statistics. Cultural and ethnic background was classified according to a combination of self-reported group identification with particular cultural or ethnic groups, the participant's birthplace and their parents' birthplaces. 


\section{References}

AlHW. (2011). 2010 National Drug Strategy Household Survey. Canberra: Australian Institute of Health and Welfare.

Anstice, S., Strike, C. \& Brands, B. (2009). Supervised methadone consumption: Client issues and stigma. Substance Use \& Misuse, 44 (6), 794-808.

Baldwin, M., Marcus, S. \& De Simone, J. (2010). Job loss discrimination and former substance use disorders. Drug \& Alcohol Dependence, 110 (1), 1-7.

Barratt, M. J. (2011). Discussing illicit drugs in public internet forums: Visibility, stigma, and pseudonymity. In J. Kjeldskov \& J. Paay (Eds), C\&T 11. Proceedings of the Fifth International Conference on Communities and Technologies. Brisbane: ACM, New York, pp. 159-168.

Bourgois, P. (2003). In search of respect: Selling crack in El Barrio. Cambridge: Cambridge University Press.

Bourgois, P. (2011). Homelessness, addiction, and politically structured suffering in the US war on drugs. In G. Hunt, M. Milhet \& H. Bergeron (Eds), Drugs and Culture: Knowledge, Consumption and Policy. Farnham: Ashgate, pp. 241-259.

Butler, J. (1993). Bodies that matter. London and New York: Routledge.

Cama, E., Brener, L., Wilson, H. \& von Hippel, C. (2016). Internalized stigma among people who inject drugs. Substance Use \& Misuse, 51 (12), 1664-1668.

Campbell, N. (2007). Discovering addiction: The science and politics of substance abuse research. Ann Arbor: University of Michigan Press.

Cape, G. (2003). Addiction, stigma and movies. Acta Psychiatrica Scandinavica, 107 (3), 163-169.

Carr, E.S. (2010). Scripting addiction: The politics of therapeutic talk and American sobriety. Princeton: Princeton University Press. 
Courtwright, D. (2010). The NIDA brain disease paradigm: History, resistance and spinoffs. BioSocieties, 5 (1), 137-147.

Dwyer, R. (2011). The social life of smokes: Processes of exchange in a heroin marketplace. In S. Fraser \& D. Moore (Eds), The drug effect: Health, crime and society. Cambridge: Cambridge University Press, pp. 19-34.

Earnshaw, V., Smith, L. \& Copenhaver, M. (2013). Drug addiction stigma in the context of methadone maintenance therapy: An investigation into understudied sources of stigma. International Journal of Mental Health \& Addiction, 11 (1), 110-122.

Fraser, S. (2008). The chronotope of the queue: Methadone maintenance treatment and the production of time, space and subjects. International Journal of Drug Policy, 17 (13), $192-$ 202.

Fraser, S. (2013). Junk: Overeating and obesity and the neuroscience of addiction. Addiction Research \& Theory, 21 (6), 496-506.

Fraser, S., Moore, D. \& Keane, H. (2014). Habits: Remaking addiction. Basingstoke: Palgrave Macmillan.

Fraser, S. \& Seear, K. (2011). Making disease, making citizens: The politics of hepatitis C. Aldershot: Ashgate.

Fraser, S. \& Treloar, C. (2006). 'Spoiled identity' in hepatitis C infection: The binary logic of despair. Critical Public Health, 16 (2), 99-110.

Fraser, S. \& valentine, k. (2008). Substance and substitution: Methadone subjects in liberal societies. Basingstoke: Palgrave Macmillan.

Goffman, E. (1973/1963). Stigma: Notes on the management of spoiled identity. Harmondsworth and Ringwood: Penguin.

Hathaway, A. D., Comeau, N. C. \& Erickson, P. G. (2011). Cannabis normalization and stigma: Contemporary practices of moral regulation. Criminology \& Criminal Justice, 11 (5), 451-469. 
Health Experiences Research Group (HERG) (2010). Researcher's Handbook for Producing HealthTalkOnline and YouthHealthTalk Websites. Health Experiences Research Group, Oxford University: Oxford.

Henderson, S., Stacey, C. L. \& Dohan, D. (2008). Social stigma and the dilemmas of providing care to substance users in a safety-net emergency department. Journal of Health Care for the Poor and Underserved, 19, 1336-1349.

Jutel, A. (2011). Putting a name to it: Diagnosis in contemporary society. Baltimore: Johns Hopkins University Press.

Keane, H. (2002). What's wrong with addiction? Melbourne: Melbourne University Press.

Keyes, K., Hatzenbuehler, M., McLaughlin, K., Link, B., Olfson, M., Grant, B. \& Hazin, D. (2010). Stigma and treatment for alcohol disorder in the United States, American Journal of Epidemiology, 172 (12), 1364-1372.

Kulesza, M., Larimer, M. \& Rao, D. (2013). Substance use related stigma: What we know and the way forward. Journal of Addictive Behaviours, Therapy \& Rehabilitation, 2 (2), 782.

Latour, B. (2010). An attempt at a 'Compositionist manifesto'. New Literary History, 41 (3), 471-490.

Livingston, J., Milne, T., Lan Fang, M. \& Amari, E. (2011). The effectiveness of interventions for reducing stigma related to substance use disorders: A systematic review. Addiction, 107 (1), 39-50.

Luoma, J., Twohig, M., Waltz, T., Hayes, S., Roget, N., Padilla, M. \& Fisher, G. (2007). An investigation of stigma in individuals receiving treatment for substance abuse. Addictive Behaviours, 32 (7), 1331-1346.

Maher, L. (1997). Sexed work: Gender, race and resistance in a Brooklyn drug market. Oxford: Oxford University Press. 
Meurk, C., Hall, W., Morphett, K., Carter, A., \& Lucke, J. (2013). What does 'acceptance' mean? Public reflections on the idea that addiction is a brain disease. BioSocieties, 8 (4), 491-506. (Open access online at:

http://dx.doi.org.dbgw.lis.curtin.edu.au/10.1057/biosoc.2013.24).

Meurk, C., Carter, A., Partridge, B., Lucke, J. \& Hall, W. (2014). How is acceptance of the brain disease model of addiction related to Australians' attitudes towards addicted individuals and treatments for addiction? BMC Psychiatry, 14, 373 (Open access online at: https://bmcpsychiatry.biomedcentral.com/articles/10.1186/s12888-014-0373-x\#Sec14).

Neale, J., Nettleton, S. \& Pickering, L. (2011). Recovery from problem drug use: What can we learn from the sociologist Erving Goffman? Drugs: Education, Prevention \& Policy, 18 (1), 3-9.

Parker, R. \& Aggleton, P. (2003). HIV and AIDS-related stigma and discrimination: a conceptual framework and implications for action. Social Science \& Medicine, 57, 13-24.

Pennay, A. \& Moore, D. (2010). Exploring the micro-politics of normalisation: Narratives of pleasure, self-control and desire in a sample of young Australian 'party drug' users. Addiction Research \& Theory, 18 (5), 557-571.

Radcliffe, P. \& Stevens, A. (2008). Are drug treatment services only for 'thieving junkie scumbags'? Drug users and the management of stigmatised identities. Social Science \& Medicine, 67, 1065-1073.

Race, K. (2008). The use of pleasure in harm reduction: Perspectives from the history of sexuality. International Journal of Drug Policy, 19 (5), 417-423.

Raikhel, E. (2016). Governing habits: Treating alcoholism in the post-Soviet clinic. Cornell University Press.

Rhodes, T., Watts, L., Davies, S., Martin, A., Smith, J., Clark, D. ...Lyons, M. (2007). Risk, shame and the public injector: A qualitative study of drug injecting in South Wales. Social Science \& Medicine, 65 (3), 572-585. 
Rivera, A., DeCuir, J., Crawford, N., Amesty, S. \& Fuller Lewis, C. (2014). Internalized stigma and sterile syringe use among people who inject drugs in New York City, 2010-2012. Drug \& Alcohol Dependence, 144, 259-264.

Room, R. (2005). Stigma, social inequality and alcohol and drug use. Drug \& Alcohol Review, 24, 143-155.

Rose, N. \& Abi-Rached, J. (2014). Governing through the brain: Neuropolitics, neuroscience and subjectivity. Cambridge Anthropology, 32 (1), 3-23.

Scambler, G. (1989). Stigma and disease: Changing paradigms. The Lancet, 352, 10541055.

Sedgwick, E. (1993). Epidemics of the Will. In her Tendencies. Durham: Duke University Press, pp. 130-142.

Simmonds, L. \& Coomber, R. (2009). Injecting drug users: A stigmatised and stigmatising population. International Journal of Drug Policy, 20 (2), 121-130.

Swalve, N. \& DeFoster, R. (2016). Framing the danger of designer drugs: Mass media, bath salts, and the 'Miami Zombie Attack'. Contemporary Drug Problems, 43 (2), 103-121.

Treloar, C. \& Holt, M. (2006). Deficit models and divergent philosophies: Service providers' perspectives on barriers and incentives to drug treatment. Drugs: Education, Prevention \& Policy, 13 (4), 367-382.

van Olphen, J., Eliason, M.J., Freudenberg, N. \& Barnes, M. (2009). Nowhere to go: How stigma limits the options of female drug users after release from jail. Substance Abuse Treatment, Prevention \& Policy, 4, 1-10.

Volkow, N. (2015). Addiction: A Disease of Free Will. The William C. Menninger Memorial Convocation Lecture. 168th Annual Meeting of the American Psychiatric Association, Toronto, Canada.

Volkow, N \& Li, T. (2004). Drug addiction: The neurobiology of behaviour gone awry. Nature Reviews Neuroscience, 963-970. 
Vrecko, S. (2010). Birth of a brain disease: Science, the state and addiction neuropolitics. History of the Human Sciences, 23 (4), 52-67.

Weinberg, D. (2005). Of others inside: Insanity, addiction and belonging in America. Temple University Press.

${ }^{1}$ Whether this is because encounters with neuroscientific accounts are limited, or fail to persuade, or because attitudes are simply inconsistent, remains incompletely researched, but see Meurk et al. (2013).

${ }^{2}$ Such understandings may also accommodate specific enactments of intoxication. 